\title{
MJN INVESTIGATING THE RELATIONSHIP BETWEEN DAILY SPIRITUAL EXPERIENCE AND CANCER PATIENTS RESILIENCE EXTENT IN IMAM KHOMEINI HOSPITAL OF TEHRAN, 2016
}

\author{
Nazanin Savaryand*, Nazi Savary \\ Faculty of Nursing and Midwifery, Isfahan Branch of Islamic Azad University, Isfahan, Iran \\ *Corresponding Author’s Email: nazaninsavary64@gmail.com
}

\begin{abstract}
Investigating the relationship between daily spiritual experience and cancer patients' resilience in Imam Khomeini Hospital of Tehran, 2016. Introduction: Reinforcing resilience is one of the effective ways of encountering and dealing with chronic diseases like cancer. Identifying the influential factors on cancer patients' resilience has a significant impact on decreasing this disease effects. From among these factors is daily spiritual experience. Therefore, the purpose of this study is to investigate the relationship between daily spiritual experience and cancer patients' resilience at Imam Khomeini hospital of Tehran, 2016. Methodology: This study was conducted through a descriptive correlational method among 234 cancer patients visiting Imam Khomeini Hospital of Tehran from September 2016 to May 2017 was included in this study. They were selected through easy Sampling Techniques. Instruments used for collecting data were reliable and valid questionnaires of personal demographic characteristics, resilience scale of Connor \& Davidson (2003) and Underwood \& Teresi (2002) scale of daily spiritual experience. The data were then analyzed in their significant levels using inferential and descriptive statistics such as Pierson correlation coefficient, multiple regression coefficient and variance analysis using $19^{\text {th }}$ version of SPSS software. Findings: Most of participants of the study were more than 50 years old $(40.3 \%)$ and married $(37.5 \%)$ with a diploma degree. There is no significant relationship between mean of daily spiritual experience of the patients and their resilience in terms of their marital state and level of education $(p>0.05)$. Mean of scores of daily spiritual experience and patients' resilience was more than the average extent (62.24 and 57, respectively). There was a significant relationship between resilience and daily spiritual experience $(p=0.002)$. According to multiple regression analysis, the best predictor for patients' resilience was the dimension of Connection to God from daily spiritual experience and $1.9 \%$ of variance signifies the resilience. Conclusion: Concerning the role of daily spiritual experience in increasing resilience, it is recommended to plan a necessary program in order for doing interventions related to spirituality by head nurses so that the patients could be able to get along with their disease by enhancing their resilience.
\end{abstract}

Keywords: Cancer, Resilience, Spiritual Experience

\section{INTRODUCTION}

Resilience is a personal adaptation to stress factors such as damages, threats, interpersonal, family, financial, sanitary and health problems and diseases which alleviate the negatives effects of stress (Basim \& Cetin, 2011). The American Psychological Institute (2014) defines resilience as an appropriate adaptation to the stress sources and problems. In in adult patients with cancer and survivors, resilience is defined as a as a dynamic process of facing adversity associated with cancer experience (Eicher et al., 2015).
Resilience is a personal characteristic which leads to positive adaptation and alleviate the negative impact of stress which is an evolutionary step that enables the patient recover and maintain his health state despite problems. Results of various studies show that resilience in patients suffering from physical chronic diseases is related to factors such as self-care, binding to cure, quality of life and self-efficacy, decreasing the depression, concerns and stress, enhancing the optimism and decreasing pessimism (Santos et al., 2013; Steinhardt et al., 2009).

Studies conducted in Iran showed that resilience 
were mainly related to psychology and psychometric domain. The study revealed the relationship between resilience and psychological, family, occupational and social aspects of individuals (Kaveh et al., 2011; Mohammadi, Aghajani \& Zehtabvar 2011).

Another study on cancer patients, showed that resilience is not in an appropriate state among cancer patient (Abdollah et al., 2015; Fakhri Razieh \& Farahnaz, 2016). Therefore, concerning the fact that cancer is the third reason for death in Iran and its consequences influences different dimensions of a patient life, effective factors of patients resilience has a direct impact on positive adaptation to cancer that decrease of the effects of the disease and increase the quality of patient life (Malekzadeh, Derakhshan \& Malekzadeh 2009). As a result, it is always regarded as an important issue to be followed on daily spiritual experience acting as one of the factors which seems to have relationship with cancer patients' resilience (Matzka et al., 2016). Culliford, (2009) considers daily spiritual experience including religious attitude, practical dimensions, mental sanitation and religious as religion has a greater connection with every human which is equivalent to life itself.

Due to threatening nature of cancer, its diagnosis demands the increased in spiritual needs of patients drastically. On one hand diagnosis of cancer disease can cause a lot of spiritual tension in an individual, sometimes his self-confidence and religious faith would be in danger. Personal communication will be disturbed also due to lack of certainty in future. Former adaptation mechanism seems to be insufficient and being hospitalized will increase the sense of loneliness (Highfield, 1992). To sum up, one can infer that this will lead to spiritual tensions in the individuals who are spiritually reinforced and will be more effectively adapted to their diseases and even better deal with last steps of disease.

Findings of different studies demonstrate that spiritual experience is placed among the most influential factors in life which helps patients to get along with their cancer disease, decreases their mental concerns and enhances their quality of life and their socio mental health. Tarakeshwar et al., (2006) and Nelson et al., (2002) showed that the feeling of comfortable and powerfulness coming from religious beliefs will be useful in becoming healthy and will help the patient to feel well (Tsevat, 2006). Religious acts may not cure a patient, but it can help them to have good feelings so that they can prevent health problems and can help them to easily get along with their disease and death (Taghavi \& Amiri,
2010). Ryan \& Caltabiano (2009) stated that religious beliefs and spirituality are effective parts of resilience which bring a feeling of hope in individuals. The results of the study by McClain, Rosenfeld \& Breitbart, (2003) demonstrated that spiritual well-being provided significant contribution beyond that of depression and has got a strong impact on the hopelessness for end-of-life despair in terminally ill cancer patient. Vellone et al., (2006) on the other hand, show no significant relationship between hopefulness and carrying out religious acts like performing prayers. In a study it was found that spiritual intelligence leads to decrease in the extent of disease and increase longevity. Moreover, spiritual intelligence significantly predicts resilience in students and supportive factors like religion and spirituality improves mental health resulting in increase in resilience (Elmer, MacDonald \& Friedman, 2003). Findings of the study by Abdelahzadeh et al., (2015) demonstrate that there is a significant relationship between spiritual intelligence and resilience in cancer patients.

Studying the literature show that many studies have been conducted on the relation between spirituality and resilience, but most of them were carried out among students, cardiovascular patients and nurses. These works were mainly based on the other spiritual dimensions like spiritual intelligence. So concerning the importance of resilience in increasing the life expectancy, decreasing the psychological effects of cancer along with the lowering of side effects of the cure, enhancement of quality of life further studies are necessary. Moreover, it has been also indicated that there is effective relationship between dimensions of resilience and spiritual experience of cancer patients. This have been dealt with for the first time in the present study. This study seeks to reply these questions:

1. How is the state of spiritual experience in cancer patients like?

2. How is the state of resilience and its dimensions in cancer patients like?

3. Is there any significant relationship between spiritual experience and cancer patient's demographic features?

4. Is there any significant relationship between resilience and cancer patients' demographic features?

5. Is there a relationship between daily spiritual experience and Imam Khomeini patients suffering from cancer?

6. Is there any relationship between the dimension of God's presence and Imam Khomeini cancer patient's resilience? 
7. Is there any significant relationship between dimension of connection to God and resilience of Imam Khomeini patients who suffer from cancer?

8. Is there any relationship between dimension of sense of responsibility for God and resilience in Imam Khomeini cancer patients?

Objective of the study:

1. Specifying the mean score of daily spiritual experience in cancer patients

2. Specifying the mean scores of resilience in cancer patients

3. Investigating the relationship between

4. Specifying the relationship between resilience in cancer patients' demographic features

5. Relationship between Daily Spiritual Experience and Cancer Patients Resilience Extent

\section{METHODOLOGY}

\section{Statistical population and sampling}

The present study was conducted in a descriptive correlational method. The statistical population were all cancer patients who visited Imam Khomeini hospital in 2016 (600 individuals).Using available sampling method, 234 individuals have been selected as samples through Cochran sampling method from September 2016 to May 2017.

\section{Measuring instruments}

In order to collect data, three questionnaires were given to each cancer patient included in the sample. The questionnaire dealt with demographic features containing 4 items consisting of 25 -item scale of resilience (Connor \& Davidson, 2003), and daily spiritual experience which have 16 items on the basis of 5-point Likert scale (Underwood \& Teresi, 2002). The content and formal validity of these questionnaires were confirmed by supervisor and reliability of the questionnaires were also measured based on Cronbach's Alpha for cancer patient resilience and daily spiritual experience as 0.89 and 0.95 , respectively. Data analysis were done at two levels of descriptive statistics (frequency, percentage, mean and Standard Deviation) and inferential statistics (Pierson correlation coefficient, multiple regression analysis and manifold variance analysis test) using 19th version of SPSS software. The normality of data was evaluated by KolmogrovSmirror.

\section{RESULTS}

1. State of spiritual experience and its dimensions in cancer patients of Tehran Imam Khomeini Hospital?

Table 1: Mean of State of Spiritual Experience in Cancer Patients of Tehran Imam Khomeini Hospital (given mean of 56)

\begin{tabular}{|l|c|c|c|c|c|c|}
\hline & Mean & $\begin{array}{c}\text { Standard } \\
\text { deviation }\end{array}$ & $\begin{array}{c}\text { Mean } \\
\text { deviation }\end{array}$ & $\begin{array}{c}\boldsymbol{T} \\
\text { value }\end{array}$ & $\begin{array}{c}\text { Degree of } \\
\text { freedom }\end{array}$ & $\begin{array}{c}\text { Significance } \\
\text { level }\end{array}$ \\
\hline $\begin{array}{l}\text { Spiritual } \\
\text { Experience }\end{array}$ & 62.24 & 0.76 & 0.049 & 8.022 & 240 & 0.001 \\
\hline
\end{tabular}

According to findings of the study in table 1, the mean of Daily Spiritual Experience of cancer patients of Imam Khomeini hospital is 62.24. Since the value of measured $\mathrm{T}$ is more than that of the table, therefore cancer patients' daily spiritual experience is more than the average level .

Table 2: Mean and standard deviations of Spirituality Experience Dimensions

\begin{tabular}{|l|c|c|}
\hline \multicolumn{1}{|c|}{$\begin{array}{c}\text { Statistical indicator } \\
\text { Scale }\end{array}$} & Mean & $\begin{array}{c}\text { Standard } \\
\text { deviation }\end{array}$ \\
\hline $\begin{array}{l}\text { Sense of God's } \\
\text { presence }\end{array}$ & 36.18 & 0.83 \\
\hline Connection to God & 19.85 & 0.81 \\
\hline Sense of responsibility for God & 7.26 & 1.37 \\
\hline
\end{tabular}

The results of second table show that the mean of sense of God's presence, connection to God and sense of responsibility for God is 36.18, 19.85 and 7.26.

2. State of resilience in cancer patients of Imam Khomeini

Table3: Mean of resilience in cancer patients (given mean: 50)

\begin{tabular}{|l|c|c|c|c|c|c|}
\hline & Mean & $\begin{array}{c}\text { Standard } \\
\text { deviation }\end{array}$ & $\begin{array}{c}\text { Mean } \\
\text { deviation }\end{array}$ & $\begin{array}{c}\boldsymbol{T} \\
\text { value }\end{array}$ & $\begin{array}{c}\text { Degree } \\
\text { of } \\
\text { freedom }\end{array}$ & $\begin{array}{c}\text { Significance } \\
\text { level }\end{array}$ \\
\hline Resilience & 57 & 0.81 & 0.051 & 5.404 & 246 & 0.001 \\
\hline
\end{tabular}

According to findings of table 3, mean of resilience in cancer patients in Imam Khomeini hospital is 57. Since the measured value of T is more than t of the table, so this state is more than the average level. 
3. Relationship between mean of Daily spiritual experience (regarding the demographic features like marital status, age and educational levels)?

Table 4: Manifold Variance Analysis of Daily Spiritual Experience (Regarding the Demographic Features Like Marital Status, Age and Educational Levels)

\begin{tabular}{|l|c|c|c|c|c|}
\hline $\begin{array}{l}\text { Statistical } \\
\text { indicator } \\
\text { Scale }\end{array}$ & $\begin{array}{c}\text { Sum of } \\
\text { squared } \\
\text { values }\end{array}$ & $\begin{array}{c}\text { Degree } \\
\text { of } \\
\text { freedom }\end{array}$ & $\begin{array}{c}\text { Mean of } \\
\text { squared } \\
\text { values }\end{array}$ & $\boldsymbol{F}$ & $\begin{array}{c}\text { Significance } \\
\text { level }\end{array}$ \\
\hline Age & 0.784 & 3 & 0.261 & 0.392 & 0.759 \\
\hline $\begin{array}{l}\text { Marital } \\
\text { status }\end{array}$ & 0.003 & 1 & 0.003 & 0.005 & 0.946 \\
\hline $\begin{array}{l}\text { Educational } \\
\text { degree }\end{array}$ & 1.386 & 3 & 0.462 & 0.692 & 0.557 \\
\hline
\end{tabular}

The results of table 4 indicate that there is no significant relationship between daily spiritual experience in terms of the demographic features like marital status, age and educational levels

4. Relationship between mean of resilience and daily spiritual experience (regarding the demographic features like marital status, age and educational levels)

Table 5: Manifold Variance Analysis of Resilience Concerning the Demographic Features

\begin{tabular}{|l|c|c|c|c|c|}
\hline $\begin{array}{l}\text { Statistical } \\
\text { indicator } \\
\text { Scale }\end{array}$ & $\begin{array}{c}\text { Sum of } \\
\text { squared } \\
\text { values }\end{array}$ & $\begin{array}{c}\text { Degree } \\
\text { of } \\
\text { freedom }\end{array}$ & $\begin{array}{c}\text { Mean of } \\
\text { squared } \\
\text { values }\end{array}$ & $\boldsymbol{F}$ & $\begin{array}{c}\text { Significance } \\
\text { level }\end{array}$ \\
\hline Age & 0.985 & 3 & 0.328 & 0.640 & 0.640 \\
\hline $\begin{array}{l}\text { Marital } \\
\text { status }\end{array}$ & 0.004 & 1 & 0.004 & 0.009 & 0.926 \\
\hline $\begin{array}{l}\text { Educational } \\
\text { degree }\end{array}$ & 2.278 & 3 & 0.909 & 1.773 & 0.153 \\
\hline
\end{tabular}

Results of table 5 demonstrate that there is no significant relationship between resilience and demographic features.

5. Relationship between daily spiritual experience and Imam Khomeini patients suffering from cancer

Table 6: Correlation Coefficient between Daily Spiritual Experience and Resilience

\begin{tabular}{|c|c|c|c|}
\hline \multicolumn{4}{|c|}{ Resilience } \\
\hline \multirow{2}{*}{$\begin{array}{l}\text { Statistic indicator } \\
\text { Predicting variable }\end{array}$} & & & \\
\hline & $\begin{array}{l}\text { Correlation } \\
\text { coefficient }\end{array}$ & $\begin{array}{c}\text { Squared correlation } \\
\text { coefficient }\end{array}$ & $\underset{\substack{\text { Significance } \\
\text { level }}}{ }$ \\
\hline Spiritual experience & $0.179^{* *}$ & 0.032 & 0.002 \\
\hline
\end{tabular}

Findings of the study in above table show that there is a significant correlation coefficient between daily spiritual experience and resilience. That is a correlation coefficient exists between daily spiritual experience and resilience $(r=0.179)$. According to specified coefficient $r^{2}, 3.2 \%$ of variance of daily spiritual experience and resilience were common. So there is significant relationship between daily spiritual experience and patients suffering from cancer.

6. Relationship between the dimension of God's presence and Imam Khomeini cancer patient's resilience

Table 7: Correlation coefficient between Dimension of God's Presence from Daily Spiritual Experience and Resilience

\begin{tabular}{|c|c|c|c|}
\hline \multicolumn{4}{|c|}{ Resilience } \\
\hline Statistic indicator & & & \\
\hline Predicting variable & $\begin{array}{c}\text { Correlation } \\
\text { coefficient }\end{array}$ & $\begin{array}{c}\text { Squared correlation } \\
\text { coefficient }\end{array}$ & $\begin{array}{c}\text { Significance } \\
\text { level }\end{array}$ \\
\hline $\begin{array}{c}\text { Sense of god's } \\
\text { presence }\end{array}$ & $0.148 *$ & 0.022 & 0.021 \\
\hline
\end{tabular}

The findings of the above table show that the correlation coefficient between God's presence and resilience is significant. That is there is a significant relationship between them $(r=0.148)$. According to $r^{2}$, $2.2 \%$ of variance between these two variables were common. So, there is significant relationship between the dimension of God's presence and cancer patient's resilience.

7. Relationship between dimension of connection to God and resilience of Imam Khomeini patients who suffer from cancer

Table 8: Correlation Coefficient Between Dimension of Connection to God and Resilience

\begin{tabular}{|l|c|c|c|}
\hline & \multicolumn{3}{|c|}{ Resilience } \\
\hline $\begin{array}{c}\text { Statistic indicator } \\
\text { Predicting variable }\end{array}$ & $\begin{array}{c}\text { Correlation } \\
\text { coefficient }\end{array}$ & $\begin{array}{c}\text { Squared correlation } \\
\text { coefficient }\end{array}$ & $\begin{array}{c}\text { Significance } \\
\text { level }\end{array}$ \\
\hline Connection to God & $0.148^{*}$ & 0.022 & 0.020 \\
\hline$p<0.05$ & & \\
\hline
\end{tabular}

Findings of table 8 demonstrate that the correlation coefficient between dimension of connection to God and resilience is significant. So, there is a significant relationship between connection to God and resilience $(r=0.148)$ based on $r^{2}, 2.2 \%$ of variance was common between these two variables. Therefore the $7^{\text {th }}$ question related to existence of relationship between these two variables is confirmed. 
8. Relationship between dimension of sense of responsibility for God and resilience in Imam Cancer patients

Table 9: Correlation Coefficient between Dimension of Sense of Responsibility for God and Resilience

\begin{tabular}{|l|c|c|c|}
\hline Criterion variable & \multicolumn{3}{|c|}{ Resilience } \\
\hline $\begin{array}{c}\text { Statistic indicator } \\
\text { Predicting variable }\end{array}$ & $\begin{array}{c}\text { Correlation } \\
\text { coefficient }\end{array}$ & $\begin{array}{c}\text { Squared correlation } \\
\text { coefficient }\end{array}$ & $\begin{array}{c}\text { Significance } \\
\text { level }\end{array}$ \\
\hline $\begin{array}{c}\text { Sense of responsibility } \\
\text { for God }\end{array}$ & $0.136^{*}$ & 0.018 & 0.033 \\
\hline
\end{tabular}

Findings of the table 9 indicate the correlation coefficient between sense of responsibility for God and patient's resilience is significant $(r=0.136)$. That is there exists a significant relationship between them. According to specification coefficient $r^{2}, 1.8 \%$ of variance between sense of responsibility for God and resilience were common. So, the relationship between these two variables is confirmed.

9. Dimensions of spiritual experience and prediction the resilience

Table 10: Multiple Correlation Coefficient of Spirituality Experience' Dimensions and Resilience

\begin{tabular}{|c|c|c|c|c|c|c|c|}
\hline \multicolumn{2}{|c|}{$\begin{array}{l}\text { Statistical indicator } \\
\text { Criterion variable }\end{array}$} & \multirow{2}{*}{$\begin{array}{c}\text { Predictor variable } \\
\text { Dimension of } \\
\text { connection to God }\end{array}$} & \multirow{2}{*}{$\begin{array}{c}\begin{array}{c}\text { Multiple } \\
\text { correlation } \\
\text { coefficient }\end{array} \\
0.139\end{array}$} & \multirow{2}{*}{$\begin{array}{c}\begin{array}{c}\text { Squared } \\
\text { Multiple }\end{array} \\
\begin{array}{c}\text { correlation } \\
\text { coefficient }\end{array} \\
0.019\end{array}$} & \multirow{2}{*}{ 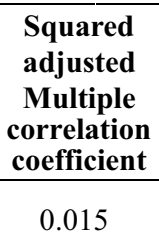 } & \multirow{2}{*}{$\begin{array}{c}F \text { coefficient } \\
4.740\end{array}$} & \multirow{2}{*}{$\begin{array}{c}\begin{array}{c}\text { Significance } \\
\text { level }\end{array} \\
0.030\end{array}$} \\
\hline Resilience & $\begin{array}{c}1^{\text {st }} \\
\text { step }\end{array}$ & & & & & & \\
\hline
\end{tabular}

As the result of table 10 show, from among variables understudy the best predictor of resilience in first step was the dimension of connection to God. According to step to step regression variance, the dimension of connection to God has a significant relationship with resilience. Based on this finding in first step, the dimension of connection to God specifies $1.9 \%$ variance of resilience. Observed $\mathrm{F}$ at level of $p<0.01$ was also significant. So, the regression is generalizable to the whole population.

Table 11: Beta Coefficient in Predicting the Spiritual Experience Dimensions with Resilience

\begin{tabular}{|c|c|c|c|c|c|c|}
\hline & \multirow{2}{*}{$\begin{array}{c}\text { Predictor } \\
\text { variable }\end{array}$} & \multicolumn{2}{|c|}{$\begin{array}{c}\text { Nonstandard } \\
\text { Beta coefficient }\end{array}$} & \multirow{2}{*}{$\begin{array}{c}\text { standard Beta } \\
\text { coefficient }\end{array}$} & \multirow{2}{*}{$\begin{array}{c}T \\
\text { value }\end{array}$} & \multirow{2}{*}{$\begin{array}{c}\text { Significance } \\
\text { level }\end{array}$} \\
\hline & & Beta & $\begin{array}{c}\text { Criterion } \\
\text { error }\end{array}$ & & & \\
\hline \begin{tabular}{|l}
$1^{\text {st }}$ \\
step
\end{tabular} & $\begin{array}{c}\text { Connection } \\
\text { to God }\end{array}$ & \begin{tabular}{|l|}
0.144 \\
\end{tabular} & 0.066 & 0.139 & 2.177 & 0.030 \\
\hline
\end{tabular}

The findings of the study in table 11 indicate that as the connection with God increases, beta coefficient increases resilience 0.0139 unit. The predicting equation would be like this:

Resilience $=(1.731)+$ dimension of connection to God (0.144)

Table 12: Relationship between dimensions of sense of God's presence, sense of responsibility for God and spiritual experience

\begin{tabular}{|l|c|c|c|c|}
\hline & Scale & Beta & T value & $\begin{array}{c}\text { Significance } \\
\text { level }\end{array}$ \\
\hline \begin{tabular}{l}
$1^{\text {st }}$ step \\
\cline { 2 - 5 }
\end{tabular} & $\begin{array}{c}\text { Sense of God's } \\
\text { presence }\end{array}$ & 0.087 & 1.100 & 0.272 \\
\cline { 2 - 5 } & $\begin{array}{c}\text { Sense of responsibility } \\
\text { for God }\end{array}$ & 0.095 & 1.359 & 0.176 \\
\hline$p<0.05$
\end{tabular}

As seen in table 12, the relationship between dimensions of sense of God's presence, sense of responsibility for God and spiritual experience was not significant

\section{DISCUSSION}

In this section main findings of the study are based on purposes. Concerning the first objective of the study i.e. specifying mean of spiritual experience and its dimensions in cancer patients was depicted in table 4, 5 . It was determined that mean of spiritual experience in cancer patients, according to the ranking of spiritual experience scale was found to be more than the average level.

There are limited number of studies regarding the extent of daily spiritual experience in patients suffering from chronic diseases such as cancer. In this respect, Hamrick \& Diefenbach (2006), in a study found out that the rate of daily spiritual experience was more intense in these patients than the average level and the obtained score was also more than general population (Abdollah zadeh, 2006). Rezaiee et al., (2006) also conducted a study in Iran, on the purpose of identifying spiritual health in cancer patients and discovered that the mean of most patients' spiritual health $(54.4 \%)$ was in a higher level (Rezaei, Seyedfatemi \& Hosseini, 2009). As far as other chronic diseases are concerned, Azimiyan, (2016), in an inquiry found the extent of spiritual experience in patients under-hemodialysis and showed that the mean score of spiritual experience was more than the average level in these patients (Azimiyan, 2016). 
In principle diagnosis of cancer can make patient feel scared, concerned, depressed and hopeless which will make him hesitant in performing his future plans and results in enhancement of his spiritual requirements as well (Vallurupalli et al., 2012). Tatsumura (2003) noted that studies in the domain of cancer indicate that most of cancer patients exploit spiritual resources to respond to their illnesses and the importance of these resources in physical, mental and meditative health has been confirmed (Tatsumura, 2003). According to Kristeller (1999) diagnosis of cancer can create concerns related to spiritual welfare, unpleasant sense and other problems. Therefore, in this case spirituality can help the patient to adapt to the disease and diagnosis and this will be useful for him (Azimiyan, 2016).

As for second purpose of this study, that is to specify the mean of resilience in patients suffering from cancer, results of table 6 show that the mean score of resilience is more than the average level based on ranking of resilience scale. Compatible to this finding, in a study based on the factors influencing cancer patients' resilience, reports that the mean score of resilience in patients suffering from blood cancer was more than the average level and society population as well (Gallager, 2016).

In Iran Abdelahzade et al., (2015), a study on specifying the relationship between spiritual intelligence and resilience in cancer patients of southern Khorasan, find out that the rate of patient's resilience is more than the average level (Abdollah zadeh, 2015). In agreement with this finding, Noori Akbari \& Salari, (2014), in a research among mental resilience in patients suffering from Coroners vascular found that the extent of resilience was more among these patients than the average level. According to studies conducted, it was determined that the resilience acts as a buffer, a protective factor in facing stressors of life like cancer disease (Vartak, 2015; Zebrack, 2011). Age is one of the factors that can have relationship with resilience in patients i.e with increase in age rate of resilience is enhanced, concerning the fact that most of the patients were more than 50 years old. This could be because of their former experience in facing the adverse events and stress in former stages of their life.

Concerning the third purpose of the study, i.e. specifying the mean score of daily spiritual experience in cancer patients, based on the demographic variables, the data and results of the table 7 show that there is no significant relationship between these two variables in terms of age, marital status and educational degrees. Lynch et al., (2012), in agreement with this found that there exists no significant relationship between marital status, age, educational levels and mean score of spiritual experience of diabetic patients $\left(2^{\text {nd }}\right.$ kind) (Lynch, 2012). In contrast to the above mentioned findings, Rezaie et al., (2006), in a research on identifying the spiritual health in cancer patients found that there is a significant relationship between patients spiritual health and their personal characteristics such as age, marital state and educational levels as there is a direct significant relationship between age and spiritual health of these patients. Spiritual health of most patients whose wife or husband was dead or divorced was in a higher level. Moreover, patients with elementary school degrees have got the highest level of spiritual health in comparison to others (Rezaei, Seyedfatemi \& Hosseini, 2009). One reason for this contrast may be the difference in research population and spirituality scale used. Also in case of other patients who suffer from other chronic diseases, Azimyan et al., (2016) find out that there is no significant relationship between mean of spiritual experience, age and educational level of patients; but in married patients, the scores were in a higher level.

Regarding the fourth objective of the study, the mean of cancer patients' resilience in terms of their demographic features, findings of the study in table 8 demonstrate that there is no significant relationship between mean of resilience as far as patients' marital state, age and educational levels were concerned. There is limited number of studies regarding the relationship between resilience and demographic variables. Abdelah et al., (2015) point out that there is no significant relationship between resilience extent and patients' age, educational levels and marital state.

Concerning the fifth objective, i.e. the relation between spiritual levels, its dimensions in cancer patients' findings of the present study as shown in table 9-12 that there is a significant relationship in this respect. As far as these dimensions are concerned, God's presence $(p=0.021)$, connection with $\operatorname{God}(p=0.020)$ and dimension of sense of responsibility for $\operatorname{God}(p=0.033)$ have got a significant relationship with resilience. Regarding the resilience prediction, in first step the dimension of connection to God was the best predictor in step to step regression analysis. Accordingly, there is also a significant relationship between resilience and connection to God. 
In this respect most of studies have been conducted on different individuals and patients suffering from chronic diseases other than cancer. Nonetheless Ozawa et al., (2017), in a study found that there is a significant relationship between resilience and spirituality. Also, in an inquiry entitled with spirituality and religions as resilience guidelines for adults' daily life, realizes that religious activities and spirituality are effective resilience strategies in individuals dealing with unpleasant conditions of life. As a result, there is improvement in quality of life, health maintenance along with personal and family protection (Reis, 2017). Mosqueiro et al., (2015) in a study regarding the effect of religion, resilience, quality of life and danger of suicide in hospitalized depressed patients discovered that there is a positive significant relationship between spirituality and resilience. In another research on spirituality and resilience and its relationship with depression on German, Dutch and English-speaking individuals found that there exists a positive significant relationship between them. As the rate of spirituality in an individual increase, the higher the resilience and as a result the chance of being depressed will be lessened (Fangauf, 2014). In a research on relationship between mental health and spiritual health in patients suffering from kidney failure realized that daily spiritual experience is the best predictor of mental health, psychological distress, sleep disorders and psychosomatic complaints in these patients (Martinznezi \& Cusodio (2014). Kim (2011) in his research onto spirituality and resilience in adults found that spirituality separately and in relationship with religion helps to increase and improve health status, expands the adaptation abilities and enhance positive results of psychological mental health and academic learning resulting in resilience among adults (Kim, 2011). Mickley \& Soeken, (1993) showed the strong correlation between religious beliefs and hope which is somehow related to resilience in cancer patients in Angola and spirituality helps to increase the sense of hope in these patients (Kim \& Esquivel 2011). So, one can come to this conclusion that daily spiritual experience provides an expanded approach for understanding and accepting pain and consequently leads to resilience in patients.

In a study in Iran it was found that spirituality significantly predicts resilience and providing supportive factors like religion and spirituality helps to increase spiritual intelligence and improving mental health resulting in enhanced rate of resilience (Elmer, Babamiri \& Dehghani, 2012). Baljani et al., (2011) in a research on the relationship between spiritual health, religion and hope in cancer patients realized that there is a significant relationship between the feeling of existential and religious health (subcategory of spiritual health) were significant predicting factors of hope. Khademi Ghasemian \& Hassanzadeh, (2014) study on the relation between resilience, psychology, spiritual experience and resilience among finance institute staffs in Sari, showed a positive significant relationship between spiritual experience and resilience in understanding individuals (Khademi Ghasemian \& Hassanzadeh, 2014).

In specifying these findings, Connor \& Davidson (2003) stated that religious beliefs and spirituality are external components which affect resilience and can inspire the sense of hope in individuals (Barrett-Connor et al., 1990). In fact, to achieve resilience in difficult situations of life individuals must seek for spirituality. Having faith and beliefs increase the resilience and helps to overcome the challenges and difficulties (White, Driver \& Warren 2010). Although in most of studies, there are no direct point of relationship between daily spiritual experience and resilience as in most of the studies religion activities was regarded as a significant way in improving patient's resilience (Baljani et al., 2011). One can state that daily spiritual experience, beside bestowing a sense of calmness due to connection with God, prepare the individual for interpersonal communication requirements. So, it can be inferred that daily spiritual experience can reinforce resilience in individuals.

\section{CONCLUSION}

In this study, the relationship between Daily Spiritual Experience and Cancer Patients Resilience Extent was investigated. There was no significant relationship between mean score of daily spiritual experience and resilience in terms of marital status, age and educational levels. In this respect specifying the mean score of daily spiritual experience, results of the study findings data analysis show that this mean was more than the average level in cancer patient.

Concerning mean of resilience in cancer patient, results also show that the mean score of resilience is more than the average level in these patients. As far as the relationship between resilience and spiritual experience and its dimensions in cancer patients was concerned, the more the score of daily spiritual experience, the more the score resilience of resilience, and in particular in regard to daily spiritual experience, 
the dimension of connection to God was the best predictor of resilience in cancer patients.

Concerning the present study results and previous studies, one can come to this conclusion that the existence of a positive significant relationship between spiritual experience and resilience is the consequence of applying appropriate methods in patients facing with life threatening events. Bearing this in mind that daily spiritual experience is incredible on one hand can increase resilience. Therefore, it is recommended to carry out the intervening plans which reinforce daily spiritual experience and as a result patients' resilience. In this manner patients can utilize the method of coping with their disease and defensive work and will as a result they will be less concerned and anxious. They will be able to keep their calmness in difficulties to better counter with their diseases.

\section{REFERENCE}

Abdollah, Z.R. \& Diefenbach, M.A. (2006). Religion and spirituality among patients with localized prostate cancer. Palliative \& Supportive Care, 4(4), pp 345-55.

Abdollah, Z.R., Moodi, M., Allahyari, A. \& Khanjani, N. (2015). The Relationship between Spiritual Intelligence and Resiliency of Patients Suffering from Cancer in South Khorasan State. Nursing of the Vulnerables, 2(3), pp 15-24.

American Educational Research Association (AERA); American Psychological Association (APA); National Council on Measurement in Education (NCME) (2014(. Standards for educational and psychological tests and manuals: American Psychological Association.

Azimiyan, J. (2016). Daily Spiritual Experience Level: Comparison between Healthy Adults and Hemodialysis Patients. International Journal of Novel Research in Healthcare and Nursing, 3(3), pp 43-48.

Baljani, E., Khashabi, J., Amanpour, E. \& Azimi, N. (2011). Relationship between spiritual well-being, religion, and hope among patients with cancer. Journal of Hayat,17(3), pp 27-37.

Barrett-Connor, E., Garland, C., McPhillips, J.B., Khaw, K-T. \& Wingard, D.L. (1990). A prospective, populationbased study of androstenedione, estrogens, and prostatic cancer. Cancer Research, 50(1), pp 169-73.

Basim, H.N. \& Cetin, F. (2011). The reliability and validity of the resilience scale for adults-Turkish version. Turk Psikiyatri Dergisi, 22(2), 104-114.

Connor, K.M. \& Davidson. J.R.T. (2003). Development of a new resilience scale: The Connor-Davidson resilience scale (CD-RISC). Depression \& Anxiety, 18(2), pp 76-82.

Culliford, L. (2009). Healing from within: Spirituality and mental health. Multifaith. Retrieved from: https://multifaiths.com/pdf/HealingFromwithin.pdf

Eicher, M., Matzka, M., Dubey, C. \& White, K., (2015). Resilience in adult cancer care: an integrative literature review. Oncology Nursing forum, 42(1), E3-16.

Elmer, L.D., Babamiri, M. \& Dehghani, M. (2012). The relationship between mental health, spiritual intelligence with resiliency in student of Kermanshah University of Medical Sciences. Jentashapir Journal of Health Research, 3(2), pp331-8.

Elmer, L.D., MacDonald, D.A. \& Friedman, H.L. (2003). Transpersonal psychology, physical health, and mental health: Theory, research, and practice. The Humanistic Psychologist, 31(2-3), pp 159-181.

Fakhri T., Razieh, S. \& Farahnaz, R. (2016). The comparison of resilience, coping style and pain catastrophizing behavior between cancer patients and normal people. Journal of Anestiology and Pain, 7(1), pp 38-48.

Fangauf, S.V. (2014). Spirituality and Resilience: New Insights Into Their Relation With Life Satisfaction and Depression. Maastricht Student Journal of Psychology and Neuroscience, 3, pp 135-150.

Gallager, K.S. (2016). Factors influencing resilience among haematological cancer survivors. Edith Cowan University, Australia. Research Online. Retrived from: https://ro.ecu.edu.au/cgi/ viewcontent.cgi?article= 
$2778 \&$ context $=$ theses

Hamrick, N. \& Diefenbach, M.A. (2006). Religion and spirituality among patients with localized prostate cancer. Palliative \& Supportive Care, 4(4), pp 345-355.

Highfield, M.F. (1992). Spiritual health of oncology patients: Nurse and patient perspectives. Cancer Nursing,15(1), pp1-8.

Kaveh, M., Alizadeh, H., Delavar, A. \& Borjali,A. (2011). Development of a resilience fostering program against stress and its impact on quality of life components in parents of children with mild intellectual disability. Iranian Journal of Exceptional Children,11(2), pp 119-140.

Khademi, M., Ghasemian, D. \& Hassanzadeh, R. (2014). The Relationship of Psychological Resilience and Spiritual Experiences with Psychological Well-being among Employees. Journal of Psychology \& Behavioral Studies, 2(3), pp105-110.

Khalatbari, J. \& Bahari, S. (2010). Relationship between resilience and satisfaction of life. Journal of Educational Psychology, 1(2), pp 83-94.

Kim, S. \& Esquivel, G.B. (2011). Adolescent spirituality and resilience: Theory, research, and educational practices. Psychology in the Schools, 48(7), pp 755-765.

Kristeller, J.L., Zumbrun, C.S. \& Schilling, R.F. (1999). I Would If I Could: How Oncologists and Oncology Nurse Adress Spiritual Distress in Cancer Patients. Psycho-Oncology, 8(5), pp 451-458.

Lynch, C.P., Hernandez-Tejada, M.A., Strom, J.L. \& Egede, L.E. (2012). Association between spirituality and depression in adults with type 2 diabetes. The Diabetes Educator, 38(3), pp 427-435.

Malekzadeh, R., Derakhshan, M.H. \& Malekzadeh, Z. (2009). Gastric cancer in Iran: epidemiology and risk factors. Archives of Iranian Medicine, 12(6), pp 576-583.

Martinez, B.B. \& Custodio, R.P. (2014). Relationship between mental health and spiritual wellbeing among hemodialysis patients: a correlation study. Sao Paulo Medical Journal, 132(1), pp 23-27.

Matzka, M., Mayer, H., Köck-Hódi, S., Moses-Passini, C., Dubey, C., Jahn, P., Schneeweiss, S. \& Eicher, M. (2016). Relationship between Resilience, Psychological Distress and Physical Activity in Cancer Patients: A CrossSectional Observation Study. PloS one,;11(4), e0154496.

McClain, C.S., Rosenfeld, B. \& Breitbart, W. (2003). Effect of spiritual well-being on end-of-life despair in terminallyill cancer patients. The Lancet, 361(9369), pp 1603-1607.

Mickley, J. \& Soeken, K., (1993). Religioausness and hope in Hispanic-and Anglo-American women with breast cancer. Oncology Nursing Forum, 20(8), pp 1171-1177

Mohammadi, A., Aghajani, M. \& Zehtabvar, G. (2011). Addiction and its relation with resilience and emotional components. Iranian Journal of Psychiatry and Clinical Psychology, 17(2), pp 136-142.

Mosqueiro, B.P., da Rocha, N.S. \& Fleck, M.P. (2015). Intrinsic religiosity, resilience, quality of life, and suicide risk in depressed inpatients. Journal of Affective Disorders, 179, pp 128-33.

Nelson, C.J., Rosenfeld, B., Breitbart, W. \& Galietta, M. (2002). Spirituality, religion, and depression in the terminally ill. Psychosomatics, 43(3), pp 213-20.

Noori Saeid, A., Akbari, B. \& Salari, A. (2014). Comparing the psychological resiliency in patients with coronary artery disease and normal subjects. Journal of Guilan University of Medical Sciences, 23(91), pp 47-52

Ozawa, C., Suzuki, T., Mizuno, Y., Tarumi, R., Yoshida, K., Fujii, K., Hirano, J., Tani, H., Rubinstein, E.B., Mimura, M. \& Uchida, H. (2017). Resilience and Spirituality in Patients with Depression and Their Family Members: A CrossSectional Study. Comprehensive Psychiatry. 77, pp 53-59. 
Reis, L.A.D. \& Menezes, T.M.O. (2017). Religiosity and spirituality as resilience strategies among long-living older adults in their daily lives. Revista Brasileira de Enfermagem, 70(4), pp 761-766.

Reza, T.S.H. \& Hamid, A. (2010). Psychoanalysis characteristic investigation Daily Spiritual Experience Scale (DSES). Biquarterly Journal of Islamic Education, 5(10), pp 149-165.

Rezaei, M., Adib-Hajbaghery, M., Seyedfatemi, N. \& Hoseini, F. (2008). Prayer in Iranian cancer patients undergoing chemotherapy. Complementary Therapies in Clinical Practice, 14(2), pp 90-97.

Rezaei, M., Seyedfatemi, N. \& Hosseini, F. (2009). Spiritual Well-being in Cancer Patients who Undergo Chemotherapy. Hayat, 14(4), pp 33-39.

Ryan, L. \& Caltabiano, M.L. (2009). Development of a new resilience scale: The Resilience in Midlife Scale (RIM Scale). Asian Social Science, 5(11), pp 39-51.

Santos, F.R.M., Bernardo, V., Gabbay, M.A., Dib, S.A. \& Sigulem, D. (2013). The impact of knowledge about diabetes, resilience and depression on glycemic control: a cross-sectional study among adolescents and young adults with type 1 diabetes. Diabetology \& Metabolic Syndrome, 5(1), pages 5.

Steinhardt, M.A., Mamerow, M.M., Brown, S.A. \& Jolly, C.A. (2009). A resilience intervention in African American adults with type 2 diabetes. The Diabetes Educator, 35(2), pp 274-284.

Taghavi, M.R. \& Amiri, H. (2010). Assess the psychometric properties Daily Spiritual Experiences Scale (DSES). Islamic Education, 5, pp185-166.

Tarakeshwar, N., Vanderwerker, L.C., Paulk, E., Pearce, M.J. \& Kasl, S.V. (2006). Prigerson HG. Religious coping is associated with the quality of life of patients with advanced cancer. Journal of Palliative Medicine, 9(3), pp 646-657.

Tatsumura, Y., Maskarinec, G., Shumay, D.M. \& Kakai, H. (2003). Religious and spiritual resources, CAM, and conventional treatment. Alternative Therapies, 9(3), pp 64-71.

Tsevat, J. (2006). Spirituality/Religion and Quality of Life in Patients with HIV/AIDS. Journal of General Internal Medicine, 21(Suppl 5), S1-S2.

Underwood, L.G. \& Teresi, J.A. (2002). The Daily Spiritual Experience Scale: Development, theoretical description, reliability, exploratory factor analysis, and preliminary construct validity using health-related data. Annals of Behavioral Medicine, 24(1), pp 22-33.

Vallurupalli, M.M., Lauderdale, M.K., Balboni, M.J., Phelps, A.C., Block, S.D., Ng, A.K., Kachnic, L.A., Vanderweele, T.J. \& Balboni, T.A. (2012). The role of spirituality and religious coping in the quality of life of patients with advanced cancer receiving palliative radiation therapy. The Journal of Supportive Oncology, 10(2), pp 81-87.

Vartak J. (2015). The Role of Hope and Social Support on Resilience in Cancer patients. Indian Journal of Mental Health, 2(1), pp 35-42.

Vellone, E., Rega, M.L. \& Galletti, C. \& Cohen, M.Z. (2006). Hope and related variables in Italian cancer patients. Cancer Nursing, 29(5), pp 356-366.

White, B., Driver, S. \& Warren, A.M. (2010). Resilience and indicators of adjustment during rehabilitation from a spinal cord injury. Rehabilitation Psychology, 55(1), pp 23-32.

Zebrack, B.J. (2011). Psychological, social, and behavioral issues for young adults with cancer. Cancer, 117(S10), pp 2289-2294. 